Betânia Moreira Cangussu Fonseca ${ }^{\mathrm{a}}$ (iD) http://orcid.org/0000-0002-1273-0794

Ana Maria Cheble Bahia Bragab iD http://orcid.org/0000-0002-8538-5880

Elizabeth Costa Dias ${ }^{c}$

(iD) http://orcid.org/0000-0003-1708-1014

a Secretaria Municipal de Saúde de Palmas, Núcleo de Saúde do Trabalhador. Palmas, TO, Brasil.

b Fundação Oswaldo Cruz (Fiocruz). Escola Nacional de Saúde Pública Sergio Arouca. Centro de Estudos da Saúde do Trabalhador e Ecologia Humana. Rio de Janeiro, RJ, Brasil.

'Universidade Federal de Minas Gerais (UFMG), Faculdade de Medicina, Departamento de Medicina Preventiva e Social. Belo Horizonte, MG, Brasil.

Contato:

Betânia Moreira Cangussu Fonseca

E-mail

betaniacangussu@gmail.com

Trabalho baseado em dissertação de mestrado intitulada A categoria território como ferramenta estratégica no planejamento das ações de vigilância em saúde do trabalhador no SUS: uma experiência participativa na região sul do município de Palmas - Tocantins, de autoria de Betânia Moreira Cangussu Fonseca, submetida à Escola Nacional de Saúde Pública Sergio Arouca em 2014.

As autoras declaram que o trabalho não foi subvencionado e que não há conflitos de interesses.

\section{Planejamento de intervenções em Saúde do Trabalhador no território: uma experiência participativa}

\author{
Planning occupational health interventions in the territory: \\ a participatory experience
}

\section{Resumo}

Introdução: a determinação social do processo saúde/doença se operacionaliza através da organização dos serviços de atenção à saúde no território. Pela observação das dinâmicas das atividades humanas e situações de risco nele materializados, com historicidade e mobilidade, é possível intervir sobre os condicionantes, riscos e impactos à saúde, em especial, do trabalhador que nele habita. Objetivo: contribuir com a reflexão sobre a importância do território na implementação da Política Nacional de Saúde do Trabalhador e da Trabalhadora, utilizando-o como instrumento de planejamento desta intervenção. Método: pesquisa-intervenção participante; realizou-se uma oficina de diagnóstico do território visando à organização das ações de intervenção em Saúde do Trabalhador utilizando-se do método do Arco e da análise do discurso. Resultados: na oficina, com treze profissionais de diferentes segmentos, identificaram-se como prioridades de intervenção o trabalho informal e o ambiente/processo de trabalho do funcionalismo público. A percepção dos principais fatores de risco e agravos conduziu às propostas de intervenção em saúde do trabalhador. Conclusão: percebeu-se na análise territorial uma poderosa ferramenta de contribuição para planejamento e execução das ações de promoção, prevenção e atenção integral à saúde dos trabalhadores.

Palavras-chave: saúde do trabalhador; território; trabalho informal; precarização.

\begin{abstract}
Introduction: the social determination of health/disease process is made operational through the organization of health care services in the territory. Interventions on the conditioning factors, risk and workers' health impacts can be made by observing - with historicity and mobility - the dynamics of human activities and risk situations materialized in a given territory. Objective: to contribute to the reflection on the importance of the territory in the implementation of the Workers' Health National Policy, using it as an instrument for planning intervention. Method: participatory intervention research adopting the Arc Method and discourse analysis; a workshop for territory diagnosis was carried out aimed at organizing the workers' health intervention actions. Results: the workshop involved 13 professionals from different areas, and identified the informal work and the environment/work process of the civil servants as priorities for intervention. The perception of the main risk factors and workers' health problems led to proposals on occupational health interventions. Conclusion: territorial analysis was considered a powerful instrument to plan and undertake actions leading to worker's health promotion, prevention and integral attention.
\end{abstract}

Keywords: occupational health; territory; informal work; precariousness. 


\section{Introdução}

A determinação social do processo saúde/doença se operacionaliza por meio da organização dos serviços de atenção integral à saúde no território. Através da observação das dinâmicas das atividades humanas e situações de risco nele materializados, com historicidade e mobilidade é possível intervir sobre os condicionantes, os riscos e os impactos à saúde, em especial, do trabalhador que nele habita. Quanto à vigilância em saúde, em especial, a saúde do trabalhador, o território é lócus de observação que se traduz em estratégia de ordenamento/organização da atenção integral da saúde dos trabalhadores.

O desenvolvimento da atenção integral à saúde dos trabalhadores, considerando sua inserção particular nos processos produtivos, que envolve ações de promoção, prevenção e vigilância, assistência e reabilitação na rede de serviços do Sistema Único de Saúde (SUS), continua desafiando gestores, técnicos e o controle social a cumprirem o preceito constitucional, regulamentado pelas Leis Orgânicas da Saúde 8.080 e 8.142 de $1990^{1}$.

Apesar das múltiplas iniciativas implementadas nos últimos 30 anos, como a Política Nacional de Saúde do Trabalhador e da Trabalhadora (PNSTT) ${ }^{1}$, com destaque para a criação da Rede Nacional de Atenção Integral à Saúde dos Trabalhadores (Renast) $^{1}$, apoiada pelos Centros de Referência em Saúde do Trabalhador (Cerest), estes ainda não estão, de fato, inseridos de modo sistemático e sustentável nas Redes de Atenção à Saúde (RAS).

Segundo a PNSTT, toda rede de saúde deve estar comprometida com o desenvolvimento da atenção integral à saúde do trabalhador, cabendo aos Cerest prover apoio matricial aos demais pontos de atenção, em especial às equipes da Atenção Básica (eAB), nos serviços especializados, de urgência e emergência, bem como na promoção e vigilância à saúde ${ }^{1}$.

Assim, a organização e implantação das ações de saúde do trabalhador na Atenção Básica/estratégia Saúde da Família (AB/eSF) adquirem particular importância para que se alcance, de fato, a cobertura universal, levando o cuidado resolutivo e de qualidade o mais próximo possível de onde as pessoas vivem e trabalham, como recomendado pela Declaração de Alma Ata em $1978^{2}$. No atual modelo de atenção integral à saúde do SUS, a Atenção Básica à Saúde (ABS) é responsável por coordenar o cuidado e ordenar as RAS ${ }^{3}$.

Embora o SUS não esteja preparado para resolver muitas das complexas questões envolvidas nas relações entre trabalho, saúde, doença e ambiente, a $A B$ é cada vez mais desafiada a responder demandas complexas, o que exige além de conhecimento técnico especializado, apoio institucional e efetivo sistema de educação permanente.

A rede de $\mathrm{AB} / \mathrm{eSF}$ é a principal porta de entrada do SUS ${ }^{1}$; está organizada por território e opera por meio de equipes multiprofissionais, o que amplia as possibilidades do estabelecimento de vínculo entre as equipes - agentes comunitários de saúde (ACS) - e a população sob responsabilidade sanitária da rede de $\mathrm{AB}$. A territorialização adquire três sentidos diferentes e complementares: a demarcação de limites das áreas de atuação dos serviços, o reconhecimento do ambiente, da população e da dinâmica social existentes nessas áreas e o estabelecimento de relações horizontais com outros serviços adjacentes e verticais. Contribui principalmente, na atenção integral à saúde do trabalhador, com atendimento, nexo, notificação de agravos, promoção e prevenção da saúde ${ }^{4}$.

Apesar de muitos usuários do SUS serem trabalhadores, o reconhecimento do trabalho como determinante do processo saúde-doença é quase inexistente ${ }^{5}$. Além disso, com a reestruturação produtiva em curso no País, cresce o número de trabalhadores informais ou precarizados que são dependentes do SUS, e a transferência de parte dos processos para o domicílio e peridomicílio dos trabalhadores aumenta a responsabilidade das equipes da Atenção Básica, pois são as únicas que têm acesso a essas unidades de produção e podem romper com a invisibilidade desse trabalho, desses trabalhadores e das situações de risco à saúde e ao ambiente ${ }^{2}$.

Dessa forma, impõe-se a ampliação e articulação das ações de vigilância em saúde epidemiológica, sanitária, ambiental e do trabalhador, sobre as quais a $\mathrm{AB}$ tem responsabilidade sanitária, além das ações assistenciais, para garantir a integralidade da ação ${ }^{6}$.

Segundo as diretrizes da Política Nacional de Atenção Básica (PNAB) ${ }^{1}$, o planejamento das ações de saúde voltadas para os trabalhadores começa pelo diagnóstico situacional de saúde no território. Inclui além do perfil demográfico, epidemiológico e ocupacional dos trabalhadores, a identificação e análise do perfil produtivo. Para tanto, é essencial que ao enfrentarem todas as dificuldades desse processo ${ }^{7}$, as equipes da $\mathrm{AB} / \mathrm{eSF}$ contem com apoio institucional, articulação intersetorial, efetiva participação da comunidade e dos trabalhadores em particular.

Esse movimento, além de constituir um exercício de construção da cidadania, permite identificar situações de vulnerabilidade, contribuindo para o processo de definição de prioridades a serem acompanhadas no planejamento de saúde local. Nesta perspectiva, o território é compreendido como sistema dinâmico de relações e expressões do processo saúde-doença, das formas de viver, adoecer e morrer 
que irão se refletir no cuidado. "É o uso do território, e não o território em si mesmo, que faz dele objeto de análise social” (p. 255) ${ }^{8}$.

O território é o lugar onde diferentes práticas, problemas de saúde e interações humanas se materializam: as pessoas constroem suas vidas, estabelecem relações de poder, relações afetivas e muitas vezes, relações de trabalho. Santos ${ }^{9}$ pondera que o espaço geográfico abriga todos os homens, de todas as instituições e de todas as organizações: a soma de coisas e relações, a natureza e a sociedade, intermediadas pelo trabalho.

O autor ${ }^{9}$ sugere avaliar as transformações ocorridas através da análise conjunta das variáveis: "tipologia das tecnologias, dos capitais, da produção, do produto, das firmas, instituições; intensidade, qualidade e natureza dos fluxos; captação dos circuitos espaciais de produção; peso dos componentes técnicos modernos na produção agrícola; expansão das agroindústrias; novas relações de trabalho no campo; desmaterialização da produção etc.” (p. 17), que são interdependentes e estão intrinsecamente relacionadas ao mundo do trabalho, sendo indispensáveis para a intervenção na realidade local.

Barcellos et al. ${ }^{10}$ observam que

se a doença é uma manifestação do indivíduo, a situação de saúde é uma manifestação do lugar. Os lugares, dentro de uma cidade ou região, são resultados de uma acumulação de situações históricas, ambientais e sociais que promovem condições particulares para a produção de doença. (p. 130)

Monken et al. ${ }^{11}$ afirmam que ao entender o território pode-se conhecer a realidade da população. Nele se inserem as relações sociais e econômicas, as condições ambientais (e de ambiente de trabalho), moradia e circulação, relações de poder, espaços políticos e culturais, mapeamento de fontes e situações de risco e vulnerabilidades, assim como processos de produção de saúde ou doença das populações nele inseridas. É possível apreender os processos e as tendências, o que contribui para diagnosticar contextos e situações de risco social. O conjunto das informações favorece um adequado monitoramento das ações executadas, sua reformulação, a busca das parcerias intersetoriais e segmentos da sociedade, incorporando efetivamente o controle social das ações sobre o território ${ }^{12}$.

Este estudo teve como objetivo analisar a proposta de territorialização adotada pela Atenção Básica enquanto mecanismo para planejar das ações de atenção integral à saúde do trabalhador, a partir das necessidades identificadas com a participação da comunidade $^{13}$. Caracteriza-se como pesquisa-intervenção que busca contribuir na construção coletiva, participativa e democrática da organização das ações de vigilância em saúde do trabalhador.

\section{Percurso metodológico}

Trata-se de estudo descritivo, exploratório, qualitativo e participativo, cuja principal unidade de análise é a organização da intervenção em Saúde do Trabalhador no território. O recorte do estudo foi a região sul do município de Palmas (TO) que possui $38,91 \%$ da população da cidade e apresenta maior vulnerabilidade socioambiental ${ }^{14}$.

Optou-se pela pesquisa participante por seu caráter político-pedagógico, de relevância e produção partilhada de conhecimento social, que possibilita ouvir os interlocutores de maneira participativa e democrática ${ }^{15}$, articulando os saberes científico e popular, a teoria e a prática. Tenciona o conhecimento das necessidades sociais, a construção conjunta de saberes contínuos e o empoderamento dos movimentos populares, promovendo a formação de indivíduos motivados a transformar os cenários sociais, enfatizando o caráter emancipatório ${ }^{15}$. A educação e ação social convertem-se em uma metodologia de transformação social global, embora local ${ }^{16,17}$.

Desta forma, realizou-se uma oficina de estudo do território, com duração de 3 dias e participação voluntária de um grupo intersetorial, contemplando um representante da Vigilância em Saúde Ambiental municipal, dois do Cerest regional de Palmas, um do Cerest estadual do Tocantins, um da gerência de Educação Popular da Secretaria Municipal de Saúde (SMS) de Palmas, um do Sindicato do Comércio do Estado do Tocantins, e sete trabalhadores da eSF que moram na região em estudo, totalizando treze participantes, com um técnico mediando as discussões.

A caracterização do território e o planejamento participativo de ações em saúde foram definidos como categorias de análise, para estabelecer estratégias de intervenção em saúde do trabalhador no território. Utilizou-se a vivência e construção do quadrilátero da formação para área de saúde (ensino, gestão, atenção e controle social), a partir da compreensão da necessidade de ultrapassagem das habilidades técnicas para a produção da subjetividade que promova a autonomia dos trabalhadores e população usuária do SUS ${ }^{18}$. Este sistema depende da formação de profissionais com postura ativa e perspectiva humanista, que sejam capazes de abordar o processo saúde-doença de maneira ampliada ${ }^{19}$.

A educação permanente em saúde, assumida como pressuposto teórico e reconhecida enquanto prática educativa inovadora e libertadora, emancipa 
os profissionais de saúde e torna-os protagonistas de sua própria história, a fim de contribuírem com suas reflexões críticas, na resolução das questões que emergem do cotidiano do trabalho, transformando a realidade ${ }^{1,17,20}$.

Freire $^{20}$ afirma que a relação entre teoria e prática exige uma reflexão crítica sobre a prática, sem a qual a teoria pode se tornar infundada. A prática educativa crítica valoriza o saber do sujeito, criando possibilidades para a construção do conhecimento. Assim, os métodos participativos de aprendizagem conferem ao facilitador o papel de educador que apresenta uma pedagogia democrática, fundada na ética, no bom senso e no respeito entre educadores e educandos, com dignidade e autonomia.

Ferreira et al. ${ }^{21}$, ressaltam alguns conceitos freirianos sobre educação e transformação do pensamento: liberdade e diálogo; conscientização, problematização e crítica; práxis enquanto reflexão e ação transformadora da realidade e subjetividade. A ideia de transformação fornece elementos para compreensão dos fundamentos de sua teoria do conhecimento.

Neste sentido, utilizou-se a técnica de problematização inspirada na educação em saúde dialógica ${ }^{22}$ para ampliar, modificar e aprofundar a compreensão dos processos vividos no território e para construir um plano intersetorial de intervenção nos problemas identificados, em especial, da saúde do trabalhador ${ }^{23}$. Entende-se que a problematização, necessária na transformação individual, social e de conscientização do indivíduo ${ }^{24}$, deve ser o eixo estruturador da educação permanente em saúde ${ }^{18}$ considerando a percepção da realidade a partir de suas problemáticas.

A condução da oficina seguiu o método do $\mathrm{Arco}^{25}$ : a) observação da realidade; b) pontos-chave; c) teorização; d) hipóteses de solução e e) aplicação à realidade.

Na etapa de observação da realidade foram formados dois subgrupos visando à identificação dos problemas existentes no território. Na identificação dos pontos-chave, os participantes refletiram sobre as possíveis causas ou determinantes desses problemas, delimitando prioridades para intervenção. Na etapa teorização foi desenvolvida a fundamentação teórica sobre as categorias território, território da saúde, território do município de Palmas, além do levantamento de dados sobre saúde do trabalhador, processos produtivos, processo saúde-trabalho-doença, riscos e agravos à saúde dos trabalhadores. Concluída essa etapa, os subgrupos desenvolveram respostas para as seguintes questões: $O$ que é necessário para a solução do problema? Que providências tomar? O que pode realmente ser feito? As respostas, ou hipóteses de soluções, foram inseridas em uma tabela contendo as colunas: o que? como? quando (curto/médio/longo prazo)? quem?, etapa considerada síntese da busca coletiva de respostas e soluções para as questões ${ }^{26}$.

Finalmente, a última etapa, denominada aplicação à realidade, permitiu a ressignificação dos conteúdos social e político reforçando o compromisso dos participantes com seu meio e validando consensualmente as hipóteses formuladas. A sistematização inicial da informação coletada nos grupos permitiu identificar as principais unidades de significado que emergiram das discussões, considerando as regularidades de fala e os sentidos frequentes dos discursos.

Na análise do discurso ${ }^{27}$, os problemas apontados e as propostas de intervenção ganharam destaque. As categorias de análise foram sistematizadas, permitindo a categorização das informações e dos problemas relacionados à saúde dos trabalhadores e a proposição de soluções, segundo a compreensão e validação do grupo.

Este estudo respeitou os princípios éticos da Resolução $\mathrm{n}^{\circ} 466$ de 12 de dezembro de 2012 e foi aprovado pelo Comitê de Ética em Pesquisa da ENSP/ Fiocruz (CAAE: 15275013.9.0000.5240) e autorizado pela Secretaria de Saúde de Palmas.

\section{Resultados e discussão}

A oficina ocorreu durante três dias sem dispersão, com a presença e o interesse de todos os participantes, que puderam manifestar experiências e opiniões. Esta observação confirma que a formação de grupos de mistos favorece a troca de experiências sobre o trabalho, estimulando a criação coletiva e abrindo possibilidades para novas abordagens de ação pública ${ }^{28}$. Os resultados permearam diversos temas da Saúde do Trabalhador no território, destacando a percepção e conhecimento prático dos participantes e a ampliação da capacidade de interpretar a realidade para transformá-la.

Esse ambiente permitiu um debate ampliado, com saberes formais e não formais, propiciando a identificação como sujeitos históricos, sociais e políticos, articulados ao contexto familiar, ao meio ambiente e à sociedade na qual se inserem. A integração entre atenção individual e coletiva e entre grupos de trabalhadores da gestão, atenção e vigilância evidenciou que o cuidado à saúde dos trabalhadores integra todos os níveis de atenção, confirmando o princípio da integralidade enquanto eixo norteador das ações de educação em saúde ${ }^{29}$. Considera-se ainda a importância da integralidade para que a universalidade e equidade da atenção à saúde se realizem na 
sua plenitude, favorecendo ao SUS perseguir os objetivos mencionados na Constituinte de $1988^{30}$.

A observação da realidade ${ }^{25}$ permitiu o autorreconhecimento crítico sobre o território e a interpretação do contexto real. Observou-se que o serviço público e a prestação de serviços (oficinas mecânicas, lava-jatos, salões de beleza, e profissionais do sexo), são as principais ocupações. Ressalta-se o predomínio do trabalho informal, autônomo ou não, nos diversos ramos de atividade, trabalhadores sem proteção social, cuja relação de trabalho não está sujeita às leis trabalhistas e que são por isso muitas vezes invisíveis aos órgãos fiscalizadores.

Em algumas situações não se observam limites físicos e territoriais, como no caso dos trabalhadores de rua; em outros, como no espaço domiciliar, verificam-se instalações improvisadas, ausência de proteção e pouco preparo do trabalhador para desempenhar as atividades. A necessidade de sobrevivência submete-o às piores condições laborais, dificultando a construção de vínculos e poder de mobilização para reivindicação das questões trabalhistas $^{31}$. As situações e os problemas de saúde vividos pelos trabalhadores deste território foram relatados em todas as atividades propostas.

A realidade da região sul é toda bem parecida, é idêntica, né? É alguma coisinha ou outra que diferencia, mas nesse sentido da saúde do trabalhador praticamente é tudo idêntico. (P1)

A grande maioria que trabalha naquela região não tem carteira de trabalho assinada, muitos trabalham com a família por conta própria, outros em empresas pequenas e informais. (P2)

As péssimas condições laborais acompanham a precariedade dos vínculos de trabalho. Foram identificadas situações de alta vulnerabilidade relacionadas ao ciclo de vida profissional em empresas ilegais, com longas jornadas e baixos salários, dentre outros ${ }^{32}$. "Estamos diante de um intenso e significativo processo de informalização e precarização da classe trabalhadora que ocorre nas formas de trabalho parcial, subcontratado e precarizado" (p. 405) ${ }^{33}$.

Iriart et al. ${ }^{34}$ comentam sobre o aumento do trabalho informal nas últimas décadas, causando a ausência de seguridade social, medidas de prevenção de riscos e baixas remunerações. O reconhecimento do trabalho formal, principalmente pela garantia dos direitos trabalhistas, é proporcional à desvalorização simbólica do trabalho informal, com repercussões na autoestima do trabalhador.

Esse aumento foi estudado nas últimas décadas por inúmeros pesquisadores. Antunes e Druck ${ }^{35}$ ressaltam as más condições de trabalho, ausência de medidas de proteção contra exposições perigosas, baixas remunerações e ausência de proteção social. As situações de risco são desconhecidas ou ignoradas em razão da necessidade de sobrevivência. Muitos ambientes de trabalho são também residência, expondo a família do trabalhador aos mesmos riscos associados à atividade ${ }^{34}$.

É importante destacar as dificuldades crescentes para distinguir os trabalhadores informais dos formais em decorrência das mudanças nas definições e conceitos. Entretanto, existe relativo consenso quanto às relações inversas observadas entre a informalidade e o bem-estar do trabalhador, qualidade de vida e saúde dessa população ${ }^{36}$.

A primeira etapa comprovou a importância do diálogo com a comunidade para contextualizar a dinâmica das interações sociais vividas no trabalho e na saúde dos trabalhadores, instrumentalizando a construção das propostas de intervenção. Para o planejamento das ações de saúde, as situações de maior vulnerabilidade social foram consideradas prioritárias na etapa seguinte da oficina.

Na identificação dos pontos-chave ${ }^{25}$, os participantes refletiram sobre as possíveis causas dos problemas identificados, delimitando como foco prioritário para intervenção o setor informal (construção civil, salões de beleza, lava-jatos e oficinas mecânicas), além do servidor público da saúde e educação.

Nesse sentido, considerando a produção compartilhada, pelo diálogo entre trabalhadores e pesquisadores, de conhecimento sobre a relação saúde, trabalho e ambiente, é oportuno lembrar as características do modelo operário italiano (grupo homogêneo, validação consensual e não delegação) para investigação das atividades de trabalho, considerando que os participantes da oficina são também trabalhadores da saúde. No grupo homogêneo considera-se a mesma experiência de trabalho; na validação consensual, o julgamento coletivo que valida a experiência de cada um; na não delegação, assume-se o julgamento sobre as condições validadas no grupo homogêneo ${ }^{37,38}$.

Na teorização ${ }^{25}$ procurou-se aprofundar, por meio de exposição dialogada, conceitos básicos e estratégias da PNSTT (território, processo saúde-trabalho-doença, riscos e agravos à saúde dos trabalhadores), utilizando linguagem apropriada de modo a construir conceitos operativos e respostas em nível de maior complexidade que não fazem parte do conhecimento natural dos participantes. 
As discussões sobre a PNSTT evidenciaram o desconhecimento dos participantes sobre sua abrangência. A temática território foi importante na preparação da intervenção em saúde do trabalhador, enquanto o conceito ampliado de saúde trouxe à reflexão as condições de saúde às quais os trabalhadores do território estão expostos. Na teorização dos riscos e agravos à saúde dos trabalhadores, a ausência do estabelecimento do nexo causal e a subnotificação foram fatores determinantes na importância da educação permanente para a implementação da PNSTT.

As discussões sobre a categoria trabalho iniciaram com sua origem "tripalium" e com os facilitadores instigando os participantes a expressar suas representações na vida das pessoas na atualidade. O exercício revelou óticas distintas, como escravidão, subsistência, identidade ou satisfação, porém, levou-os a concluir que esses são fatores de adoecimento, e a identificarem-se como trabalhadores pertencentes àquele contexto social.

Atribuíram ao vínculo precário de trabalho os riscos à saúde existentes nos ambientes e processos de trabalho da construção civil, salões de beleza, lava-jatos e oficinas mecânicas. Nos fatores de risco ergonômico, psicológico e de acidentes, foram mencionadas situações de: ausência de treinamento ou capacitação, sobrecarga de trabalho, jornada intensa e pressão por produtividade. Apesar da possibilidade de ocorrência de acidentes e adoecimentos nessas atividades, há poucas notificações, geradas pela dificuldade em estabelecer a conexão entre adoecimento e trabalho.

Vasconcellos ${ }^{39}$ discute a junção dos elementos saúde, trabalho e direito, enquanto objetos de desejo do ser humano. Afirma que, quando combinados, proporcionam saúde no trabalho, o sonho do bem-estar. Analisa-os com foco na perspectiva histórica e sociopolítica coletiva, categorias de análise centrais nas políticas públicas que são transformadoras da realidade social e segundo as quais o trabalho não deve ser fonte de doença e morte.

A etapa de teorização ${ }^{25}$ permitiu-nos refletir sobre a importância da educação permanente na implementação da PNSTT, visto que, proporcionou ao grupo, a sensibilização e ampliação do olhar sobre a saúde dos trabalhadores.

Por fim, os participantes se reuniram em dois grupos para formulação das hipóteses de solução aos problemas prioritários do território, seguindo o roteiro: $O$ que precisa acontecer para que o problema seja solucionado? O que precisa ser providenciado? O que pode realmente ser feito? Como? De que forma? Quando? (curto/médio/longo prazo)? Por quem?.

No Quadro 1 são apresentadas as possíveis ações de intervenção nas condições de trabalho de servidores públicos da saúde e da educação da região sul de Palmas.

Os trabalhadores da saúde e educação propuseram a realização das ações de vigilância nos ambientes de trabalho por técnicos do Cerest e sindicatos da categoria, com encaminhamento aos gestores. A proposta de intervenção nas escolas deverá conter entrevistas com os profissionais da área.

Nos conflitos evidenciados destacam-se a educação permanente e valorização de todos os saberes, através do diálogo, do empoderamento dos trabalhadores e da cogestão dos processos de trabalho, como contribuição à melhoria da organização deste processo de trabalho.

No Quadro 2 são apresentadas as possíveis ações de intervenção nas condições de trabalho da construção civil, oficinas mecânicas, lava-jatos, salões de beleza, servidores públicos da saúde e da educação, na região sul de Palmas.

Quadro 1 Hipóteses de soluções para melhoria das condições de trabalho nos serviços públicos de saúde e educação do território da região sul de Palmas (TO)

\begin{tabular}{|c|c|c|c|c|}
\hline & Oque? & Como? & Quando? & Quem? \\
\hline Grupos & $\begin{array}{l}\text { Melhoria nas condições dos ambientes e } \\
\text { processos de trabalho: } \\
\text { - Reforma das Unidades Básicas de Saúde } \\
\text { (UBS); } \\
\text { - Aquisição de mobiliários e equipamentos; } \\
\text { - Aumento no número de funcionários; } \\
\text { - Distribuição de funções; } \\
\text { - Adequação de carga horária; } \\
\text { - Capacitação e treinamento dos funcionários. }\end{array}$ & $\begin{array}{l}\text { Realizando ações de } \\
\text { vigilância nos ambientes } \\
\text { e processos de trabalho } \\
\text { nesses locais. } \\
\text { - Vontade política; } \\
\text { - Ouvir trabalhadores } \\
\text { antes das tomadas de } \\
\text { decisões; } \\
\text { - Realizar processo } \\
\text { seletivo para admissão de } \\
\text { novos funcionários. }\end{array}$ & Médio prazo & $\begin{array}{l}\text { - Gestores Públicos, } \\
\text { - Atenção Básica, } \\
\text { - RH da SMS e SME de Palmas, } \\
\text { - Cerest, } \\
\text { - Sindicatos, } \\
\text { - Vigilância Sanitária. }\end{array}$ \\
\hline
\end{tabular}


Quadro 2 Hipóteses de soluções para melhoria das condições de trabalho na construção civil, oficinas mecânicas, lava-jatos, salão de beleza do território da região sul de Palmas (TO)

\begin{tabular}{|c|l|l|l|l|}
\hline \multirow{4}{*}{ Grupos } & \multicolumn{1}{|c|}{ O que? } & \multicolumn{1}{|c|}{ Como? } & Quando? & \multicolumn{1}{c|}{ Quem? } \\
\cline { 2 - 5 } & $\begin{array}{l}\text { - Implantação da cultura de saúde do } \\
\text { trabalhador com os trabalhadores e } \\
\text { conscientização do empregador }\end{array}$ & $\begin{array}{l}\text { - Visitas in loco; orientação aos } \\
\text { trabalhadores sobre riscos, acidentes, } \\
\text { agravos e prevenção e promoção. } \\
\text { - Palestras educativas }\end{array}$ & Curto prazo & $\begin{array}{l}\text { - Cerest, } \\
\text { - Sindicatos, } \\
\text { - Atenção Básica. }\end{array}$ \\
\hline
\end{tabular}

Vieira et al. ${ }^{40}$ destacam a importância da participação das eAB/eSF na realização dessas ações, por meio da criação de mecanismos de coleta de informação da situação de trabalho informal, com o intuito de identificar e avaliar os riscos existentes nos bairros, nas ruas e no interior dos domicílios, geralmente desconhecidos.

Dias e Silva ${ }^{2}$ ressaltam a importância dos ACS para realização de ações educativas com os trabalhadores usuários do SUS, em decorrência do vínculo que facilita o diálogo com os trabalhadores, a identificação dos riscos e agravos envolvidos neste processo e as possibilidades e meios de prevenção e proteção da saúde. Essas ações envolvem a orientação sobre os serviços de saúde disponíveis, fluxos de atendimento e direitos trabalhistas e previdenciários. Além disso, as eAB/eSF podem formar grupos específicos de acordo com as necessidades e demandas da população.

As atividades de educação permanente e ações de orientação sobre prevenção dos riscos e doenças relacionadas ao trabalho estavam entre as hipóteses de soluções para melhoria das condições de trabalho em todos os segmentos analisados, tendo o Cerest, a Atenção Básica e os sindicatos como principais atores nessa intervenção.

Na aplicação à realidade ${ }^{25}$ os grupos validaram consensualmente as hipóteses de soluções aos problemas identificados e observou-se que os resultados foram bastante semelhantes, apresentando poucas variações.

A análise territorial trouxe informações sobre os tipos de vínculo empregatício existentes, as condições e processos de trabalho a que estão expostos, a identificação dos riscos e agravos e o contexto social, político e cultural que os envolve. Observou-se que ainda está distante a efetivação das políticas públicas do SUS: atenção integral à saúde dos trabalhadores, independente do vínculo empregatício, através do princípio da universalidade.

Os agentes comunitários de saúde sobressaíram-se nas discussões. Conhecem a realidade dos trabalhadores locais, relatos importantes sobre relações de trabalho e desamparo social e também a forma de abordagem aos trabalhadores, fato que favorece a integração e efetividade das ações de promoção à saúde.
As hipóteses de soluções apresentadas contribuirão para a promoção da saúde dos trabalhadores e prevenção de agravos através de ações intra e intersetoriais.

É interessante destacar que embora a metodologia tenha sido apresentada em etapas, o trabalho ocorreu de modo dinâmico, encadeado e interligado, pela adoção da teoria da problematização. A troca de conhecimentos e saberes e teoria e prática foi bem articulada, permitindo a abordagem de temas não identificados, anteriormente, na etapa de teorização. A pesquisa participante associada às metodologias ativas de aprendizagem possibilitou o envolvimento dos atores e a riqueza do discurso, através da manifestação de conhecimentos, experiências, opiniões e emoções.

Entre os limites deste estudo salienta-se que o período de realização da oficina foi insuficiente para discutir todas as questões relativas a assunto tão complexo, o que aponta para a necessidade de as equipes técnicas da Vigilância em Saúde, em especial da vigilância em saúde do trabalhador, investirem suas ações na educação permanente e no apoio matricial às equipes do SUS, o que deverá ser prioridade no planejamento e na execução das atividades.

\section{Considerações finais}

Os resultados deste estudo mostram a importância da categoria território no planejamento e execução das intervenções em saúde, em especial de saúde do trabalhador. Apesar da presença dessa categoria nas normas e diretrizes do SUS, supõe-se que o planejamento das ações, considerando o diagnóstico situacional do território, ainda não está plenamente incorporado na prática das equipes de saúde.

O método utilizado proporcionou adesão e envolvimento e confirmou ser adequado para o planejamento de ações em sintonia com as necessidades do território. Ele permite escolher formas de intervenção capazes de mudar a realidade de saúde da população por meio do envolvimento e participação dos atores sociais no processo. 
Nesse contexto, o momento é de redefinir o papel do Cerest na rede, em que o planejamento das intervenções deve partir do território da Atenção Básica à Saúde, porta de entrada do SUS e espaço de implementação da PNSTT. É necessário que o Cerest invista seus esforços no apoio matricial e educação permanente com o objetivo de instrumentalizar e sensibilizar as equipes. O contexto viabilizará a inserção das equipes nas ações de atenção integral à saúde dos trabalhadores, principalmente as relacionadas à promoção, prevenção e vigilância, que deverão ocorrer através de participações intra e intersetoriais nos territórios adscritos.
Além disso, é importante que os gestores públicos propiciem as condições necessárias para melhorar a organização dos ambientes e processos de trabalho dos funcionários do SUS, para que cumpram seu papel de cuidadores da saúde da população. Tais aspectos exercem influência direta na qualidade destas ações e devem ser observadas a fim de não comprometerem a efetividade de todo o sistema.

Espera-se que esta discussão contribua para a implementação da PNSTT no SUS, para os esforços de aperfeiçoamento da Renast, na perspectiva de uma rede temática no modelo das RAS e para a ressignificação do papel dos Cerest estaduais, regionais e municipais.

\section{Contribuições de autoria}

Fonseca BMC, Braga AMCB e Dias EC participaram do planejamento do projeto e do apoio conceitual e metodológico. Fonseca BMC coletou os dados e junto com Braga AMCB fizeram a interpretação dos resultados. As três autoras contribuíram igualmente na redação, revisão crítica intelectual do manuscrito e na aprovação da versão final publicada, e assumem responsabilidade pública pelo seu conteúdo.

\section{Referências}

1. Brasil. Ministério da Saúde. Portaria de Consolidação n ${ }^{\circ}$ 2, de 28 de setembro de 2017. Consolidação das normas sobre as políticas nacionais de saúde do Sistema Único de Saúde. Diário Oficial da União. 3 out 2017.

2. Dias EC, Silva TL. Possibilidades e desafios para a atenção integral à saúde dos trabalhadores na Atenção Primária. In: Dias EC, Silva TL, organizadores. Saúde do trabalhador na atenção primária à saúde: possibilidades, desafios e perspectivas. Belo Horizonte: Coopmed; 2013. p. 21-42.

3. Giovanella LA, Patty F. Atenção primária integral e sistemas segmentados de saúde na América do Sul. Cad Saúde Pública. 2017;33(2):1-21.

4. Pereira MPB, Barcellos CC. O Território no Programa de Saúde da Família. Hygeia. 2006;2(2):47-55.

5. Dias EC, Silva TL, Chiavegatto CV, Reis JC, Campos AS. Desenvolvimento de Ações de Saúde do Trabalhador no SUS: a estratégia da Rede Nacional de Atenção Integral à Saúde do Trabalhador (Renast). In: Gomez CM, et al., organizadores. Saúde do Trabalhador na Sociedade Brasileira Contemporânea. Rio de Janeiro: Editora Fiocruz; 2011. p. 161-80.

6. Brasil. Ministério da Saúde. Portaria de Consolidação $\mathrm{n}^{\circ}$ 6, de 28 de setembro de 2017. Consolidação das normas sobre o financiamento e a transferência dos recursos federais para as ações e os serviços de saúde do Sistema Único de Saúde. Diário Oficial da União. 3 out 2017.
7. Dias EC, Silva TL, Almeida MHC. Desafios para a construção cotidiana da Vigilância em Saúde Ambiental e em Saúde do Trabalhador na Atenção Primária à Saúde. Cad Saúde Colet. 2012;20(1):15-24

8. Santos M. O retorno do território. OSAL: Observatório Social de América Latina. 2005;6(16):251-61.

9. Santos M. Metamorfoses do espaço habitado. 4a ed. São Paulo: Hucitec; 1988.

10. Barcellos CC, Sabroza PC, Peiter P, Iñiguez Rojas L. Organização espacial, saúde e qualidade de vida: análise espacial e uso de indicadores na avaliação de situações de saúde. Inf Epidemiol SUS. 2002;11(3):129-38.

11. Monken M, Barcellos C, Porto MFS. Saúde, trabalho, ambiente e território: contribuições teóricas e propostas de operacionalização. In: Gomez CM, et al., organizadores. Saúde do trabalhador na sociedade brasileira contemporânea. Rio de Janeiro: Editora Fiocruz; 2011. p. 161-80.

12. Rigotto RM, Augusto LGS. Saúde e ambiente no Brasil: desenvolvimento, território e iniqüidade social. Cad Saúde Pública. 2007;23(4):475-85.

13. Santos AL, Rigotto RM. Território e territorialização: incorporando as relações produção, trabalho, ambiente e saúde na atenção básica à saúde. Trab Educ Saúde 2010;8(3):387-406.

14. Instituto Brasileiro de Geografia e Estatística. Contagem Populacional Censo 2010 [Internet]. 
2011 [citado em 21 out 2019]. Disponível em: https:/www.ibge.gov.br/estatisticas/sociais/ populacao/9662-censo-demografico-2010. html?edicao $=9673 \& \mathrm{t}=$ sobre

15. Brandão CR. A pesquisa participante e a participação da pesquisa: Um olhar entre tempos e espaços a partir da América Latina. In: Brandão CR, Streck DR, organizadores. Pesquisa participante: o saber da partilha. 2a ed. Aparecida: Ideias e Letras; 2006. p. 21-54.

16. Goldstein AR, Barcellos C, Magalhães MAFM, Gracie R, Viacava, F. A experiência de mapeamento participativo para a construção de uma alternativa cartográfica para a ESF. Ciênc Saúde Colet. 2013;18(1):45-56.

17. Freire P. Pedagogia do oprimido. 18a ed. Rio de Janeiro: Paz e Terra; 1998.

18. Ceccim RB, Feuerwerker LCM. O quadrilátero da formação para a área da saúde: ensino, gestão, atenção e controle social. Physis. 2004;14(1):41-65.

19. Figueiredo MD. A construção de práticas ampliadas e compartilhadas em saúde: apoio Paideia e formação [tese]. Campinas: Universidade Estadual de Campinas: 2012.

20. Freire P. Pedagogia da autonomia: saberes necessários à prática educativa. São Paulo: Paz e Terra; 1996.

21. Ferreira RV, Santos MBM, Sousa KR. Educação e transformação: significações no pensamento de Paulo Freire. Revista e-Curriculum. 2014;12(2):1418-39.

22. Batista N, Batista SH, Goldenberg P, Seiffert O, Sonzogno MC. O enfoque problematizador na formação de profissionais da saúde. Rev Saúde Pública. 2005;39(2):231-7.

23. Pessoa VM, Rigotto RM, Carneiro FF, Teixeira ACA. Sentidos e métodos de territorialização na atenção primária à saúde. Ciênc Saúde Colet. 2013;18(8):2253-62.

24. Gomes LB, Mehry EE. Compreendendo a educação popular em saúde: um estudo na gestão participativa das políticas de saúde. Physis. 2011;14(1):67-83.

25. Bordenave JED, Pereira AM. O que é ensinar. In: Bordenave JED, Pereira AM. Estratégias de ensinoaprendizagem. Petrópolis: Vozes; 2000. p. 39-57.

26. Hurtado CN. Uma consulta cidadã participativa: o caso do estado de Michoacán, México. In: Brandão CR, Streck DR, organizadores. Pesquisa participante: o saber da partilha. 2a ed. Aparecida: Ideias e Letras; 2006. p. 189-225.

27. Minayo MCS. O desafio do conhecimento: pesquisa qualitativa em saúde. 12a ed. São Paulo: Hucitec; 2010.
28. Souza KR, Braga AMCB, Rozemberg B. Formação em saúde do trabalhador e saúde ambiental: avaliação de experiência com atores locais. Saúde Debate. 2017;41(114):976-85.

29. Machado MFAS, Monteiro EMLM, Queiroz DT, Vieira NFC, Barroso MGT. Integralidade, formação de saúde, educação em saúde e as propostas do SUS: uma revisão conceitual. Ciênc Saúde Colet. 2007;12(2):335-42.

30. Pinheiro R, Ferla A, Silva Jr. AG. Integrality in the population's health care programs. Ciênc Saúde Colet. 2007;12(2):343-9.

31. Lourenço EAS. Reestruturação produtiva, trabalho informal e a invisibilidade social do trabalho de crianças e adolescentes. Serv Soc Soc. 2014;118:294-317.

32. Organización Internacional del Trabajo. Políticas para la formalización de las micro y pequeñas empresas en América Latina: experiencias, avances y desafios. Santiago: Linda Deelen; 2015.

33. Antunes R. Os modos de ser da informalidade: rumo a uma nova era da precarização estrutural do trabalho? Serv Soc Soc. 2011;107:405-19.

34. Iriart JAB, Oliveira RP, Xavier SS, Costa AMS, Araújo GR, Santana VS. Representações do trabalho informal e dos riscos à saúde entre trabalhadoras domésticas e trabalhadores da construção civil. Ciênc Saúde Colet. 2008;13(1):165-74.

35. Antunes R, Druck G. Terceirização como regra? Rev TST. 2013;79(4):214-31.

36. Corseuil CH, Reis MC, Brito AS. Critérios de classificação para ocupação informal: consequências para a caracterização do setor informal e para a análise de bem-estar no Brasil. Estud Econ. 2015;45(1):5-31.

37. Muniz HP, Brito J, Souza KR, Athayde M, Lacomblez M. Ivar Oddone e sua contribuição para o campo da saúde do trabalhador no Brasil. Rev Bras Saúde Ocup. 2013;38(128):280-91.

38. Oddone I, Marri G, Gloria, S. Ambiente de trabalho: a luta dos trabalhadores pela saúde. São Paulo: Hucitec; 1986.

39. Vasconcellos LCF. As relações saúde-trabalhodireito e a justiça injusta. In: Vasconcellos LCF, Oliveira MHB, organizadores. Saúde, trabalho e direito: uma trajetória crítica e a crítica de uma trajetória. Rio de Janeiro: Educam; 2011.

40. Vieira, MCF, Dias EC, Mattos RC. Contribuição da Atenção Primária para a saúde do trabalhador informal, no domicílio. In: Dias EC, Silva TL, organizadores. Saúde do Trabalhador na Atenção Primária à Saúde: possibilidades, desafios e perspectivas. Belo Horizonte: Coopmed, 2013. p. 308-329. 